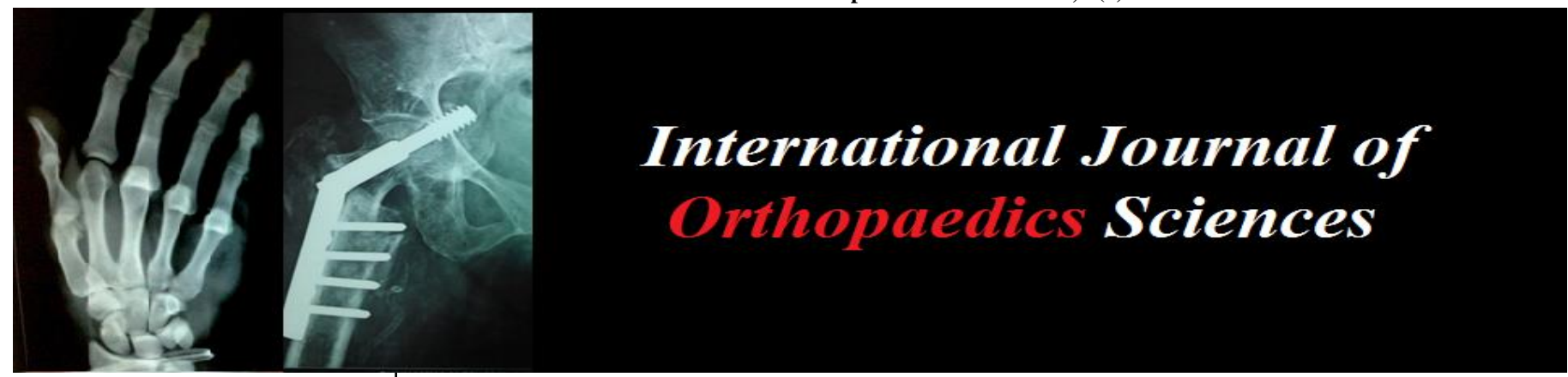

E-ISSN: 2395-1958

P-ISSN: 2706-6630

IJOS 2019; 5(4): 79-82

(C) 2019 IJOS

www.orthopaper.com

Received: 21-08-2019

Accepted: 25-09-2019

Dr. Mizanur Rahaman Junior Resident,

Department of Orthopaedics, Sri Devaraj Urs Medical College,

Tamaka, Kolar, Karnataka, India

Dr. Nagakumar JS

Professor \& Head of the unit,

Department of Orthopaedics,

Sri Devaraj Urs Medical College,

Tamaka, Kolar, Karnataka,

India

Dr. Eswara Reddy G

Assistant Professor,

Department of Orthopaedics,

Sri Devaraj Urs Medical College,

Tamaka, Kolar, Karnataka,

India

Dr. Madamanchi Harsha

Junior Resident,

Department of Orthopaedics,

Sri Devaraj Urs Medical College,

Tamaka, Kolar, Karnataka,

India

\section{Role of austin moore prosthesis in intracapsular fracture neck of femur in elderly}

\author{
Mizanur Rahaman, Nagakumar JS, Eswara Reddy G and Madamanchi \\ Harsha
}

DOI: https://doi.org/10.22271/ortho.2019.v5.i4b.1654

\section{Abstract}

Background: In elderly people neck of femur fractures are common. For which hemiarthroplasty is most popular surgery doing by an orthopaedic surgeon. Usually hemiarthroplasty can perform either with unipolar or bipolar prosthesis.

Purpose: The aim of this study is to know the outcome of unipolar prosthesis in elderly patients presented with fracture neck of femur.

Materials and Methods: From October 2014 to October 2016, 30 patients aged above 60 years who were admitted in the department of orthopaedics in R.L Jalappa Hospital, kolar were included. Functional outcome were assessed with Harish Hip Score.

Results: The study included 53\% females and $47 \%$ males. $47 \%$ were in the age group of $70-79$, followed by $43 \%, 10 \%$ were 60 to 69 years and $80-89$ years age groups respectively. Left sided hip fracture was $57 \%$ which is more than Right sided hip fracture 43\%. Fracture was classified as per Garden classification, Type IV were 14, Type III 12 and Type II 4. Most commonly used prosthesis size was 47 ranged from 39 to 49.After 6 months follow-up outcome analyzed by Harris hip score and found to be Excellent $47 \%$, Good $27 \%$, fair $20 \%$ and poor in $6.6 \%$. $13 \%$ of the study subjects had complication like superficial infections and bed sore which was treated with regular dressings and antibiotics.

Conclusion: Austin Moore prosthesis gives a better function, safe operation, lesser pain and improved gait function outcome even in elderly with significant medical problems.

Keywords: Austin moore prosthesis, unipolar, hemiarthroplasty, fracture neck of femur

\section{Introduction}

Fracture neck of femur remains an unsolved fracture and occur mostly in elderly patients due to minor to moderate trauma while in younger patients it usually result from high energy trauma ${ }^{[1]}$.

A successful operation at the hip joint should provide painless, stable hip with a wide range of movements. The first efforts on treating hip fractures concentrated on alignment of fracture fragments by closed reduction and traction and maintained by long term traction, spica cast or internal fixation. However, despite the most accurate anatomic alignment and most rigid fragment fixation, many patients failed to regain normal use of their hips. Hemiarthroplasty with Austin Moore prosthesis is rarely employed in the developed countries though it is very commonly used in developing countries like India. It should ideally be reserved for very limited or non-ambulatory patients ${ }^{[2]}$.

This study includes uncemented unipolar hip arthroplasty with Austin Moore prosthesis for fracture neck of femur in elderly. The follow up of these cases were done to assess the end results, especially as related to our Indian patients in and around Kolar District of Karnataka.

\section{Objective}

1. To study the functional outcome following hemiarthoplasty.

2. To study the morbidity and mortality rate associated with the Austin Moore prosthesis.

Materials and Methods

It is a hospital based prospective study. Fracture neck of femur in patients of age 60 years and
Dr. Nagakumar JS

Professor \& Head of the unit,

Department of Orthopaedics,

Sri Devaraj Urs Medical College,

Tamaka, Kolar, Karnataka,

India 
above were included in this study. Patients who were non ambulatory, prior to the fracture and Patients with dementia and Pathological fractures were excluded.

Primary hemireplacement arthroplasty of the hip was done in 30 patients with fracture neck of femur using Austin Moore prosthesis who were admitted in the Department of Orthopaedics in R.L Jalappa Hospital, kolar from October 2014 to October 2016. Informed consent was taken to prior to the study. X-ray of the pelvis with both hips, anteroposterior view was taken with both the limbs in 15 degree of internal rotation. Functional outcome were assessed with Harish Hip Score.

\section{Results}

The study included 16(53\%) females and 14(47\%) males. $14(47 \%)$ were in the age group of $70-79$, followed by $13(43 \%), 03(10 \%)$ were 60 to 69 years and 80-89 years age groups respectively. The mean age of the study subjects was 69 years. Left sided hip fracture was $17(57 \%)$ which is more than Right sided hip fracture 13(43\%).Fracture was classified as per Garden classification, Type IV were 14(47\%), Type III 12(40) and Type II 4(13\%).

\section{Distribution of study subjects according to type of} fracture.

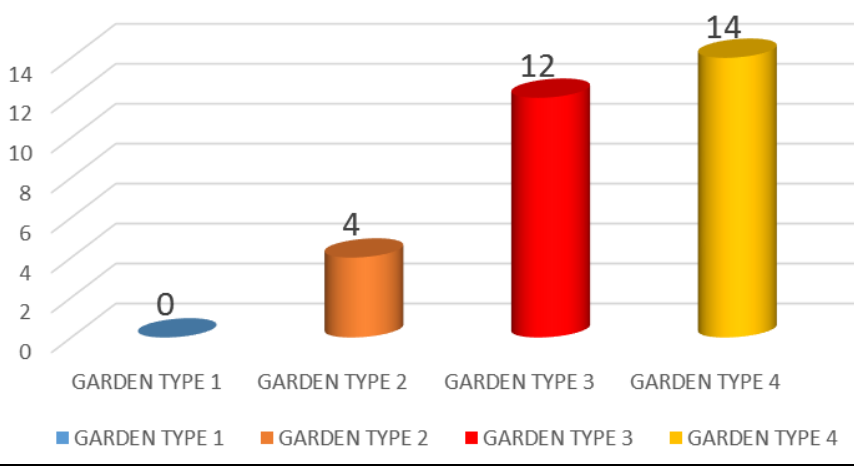

Fig 1: Distribution of study subjects according to type of fracture

Fall was the most common mode of injury (86.7\%), among then $(13.3 \%)$ were fall from height and $(13.3 \%)$ were by road traffic accident.

The size of prosthesis ranged from 39 to 49 and most commonly used size was 47 .

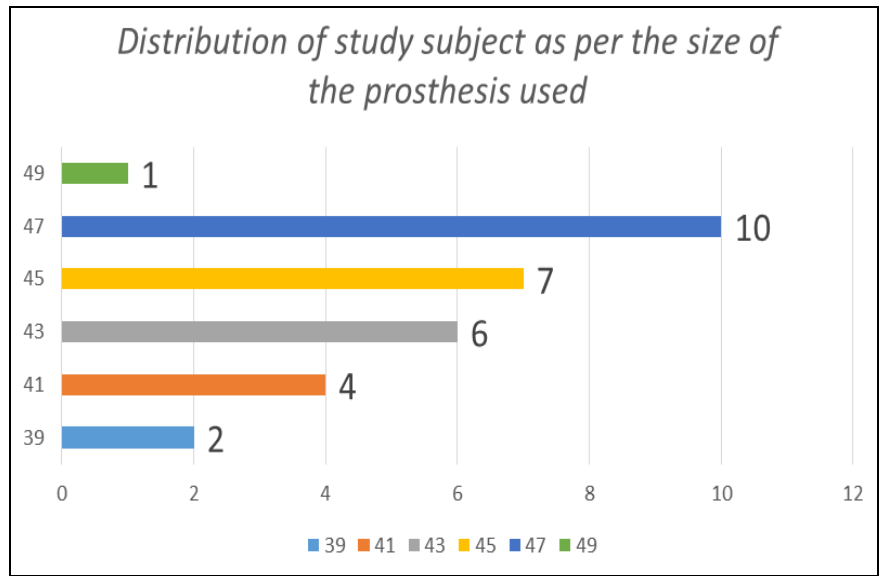

Fig 2: Distribution of study subject as per the size of the prosthesis used
Co-morbid conditions were seen in $50 \%$ of the cases. $20 \%$ had hypertension, $17 \%$ had diabetes mellitus, 3\% had ischemic heart diseases and $10 \%$ had both hypertension and diabetes.

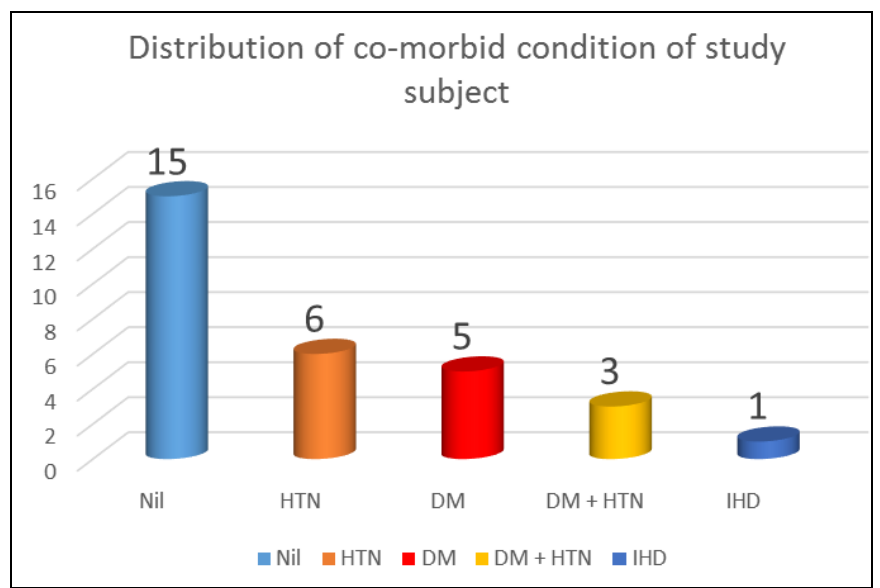

Fig 3: Distribution of co-morbid condition of study subject

$13 \%$ of the study subjects had complication among which 2 had superficial infections and 2 had bed sore which was treated with regular dressings and antibiotics.

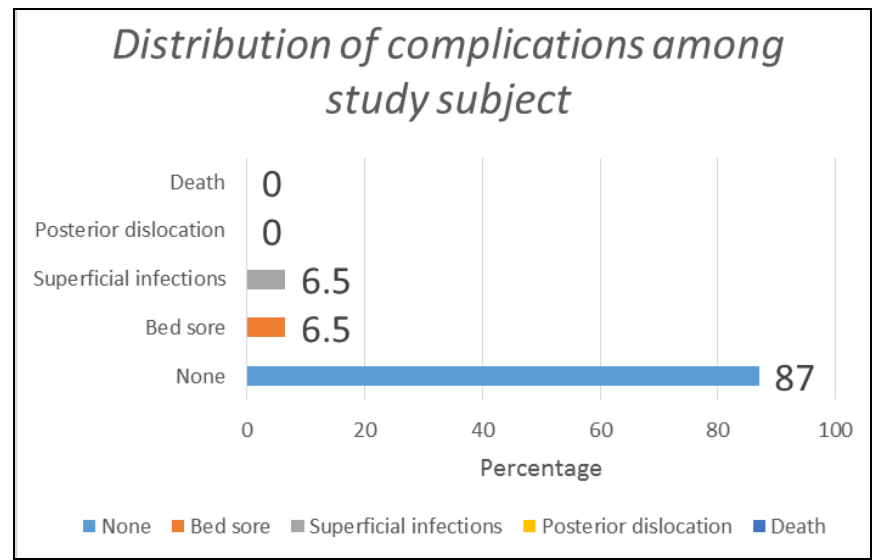

Fig 4: Distribution of complications among study subject

All the subjects were encouraged to ambulate after 3 days of surgery among which $70 \%$ were able to ambulate after 3 days and $30 \%$ took 5 days to ambulate.

Functional outcome and clinical results were assessed as per Harris Hip Score which shows:

Table 1: Functional outcome by using Harris hip score

\begin{tabular}{|c|c|c|c|}
\hline Grade & Harris Hip Score & No. of patients & Percentage \\
\hline Excellent & $90-100$ & 14 & 46.7 \\
\hline Good & $80-89$ & 8 & 26.7 \\
\hline Fair & $70-79$ & 6 & 20 \\
\hline Poor & $<70$ & 2 & 6.6 \\
\hline
\end{tabular}
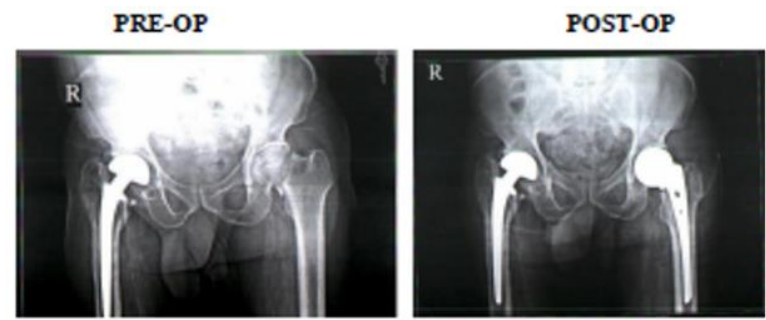


\section{FOLLOW UP}
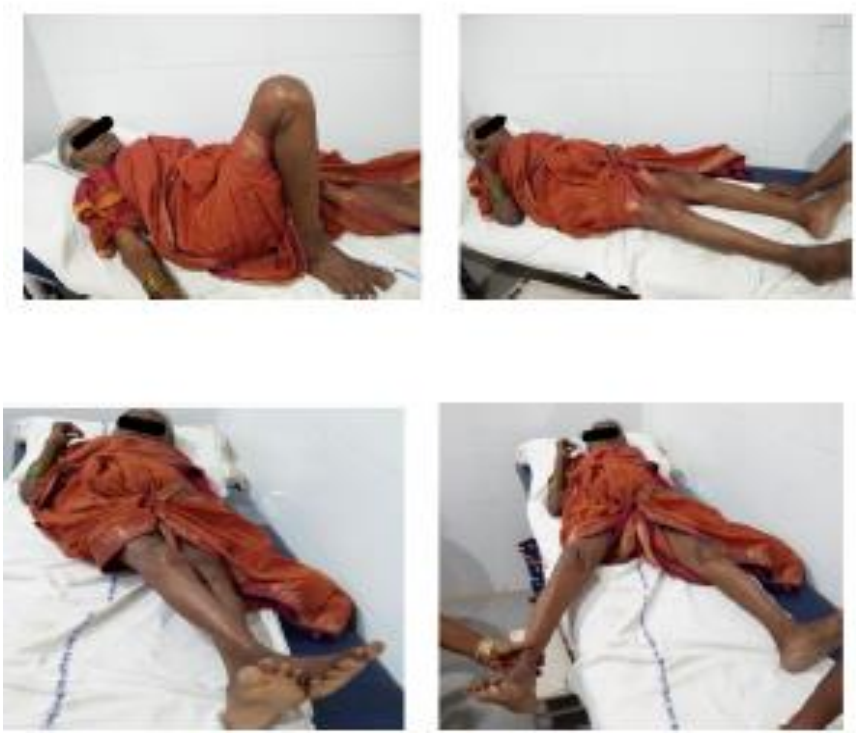

PRE-OP

\section{POST-OP}
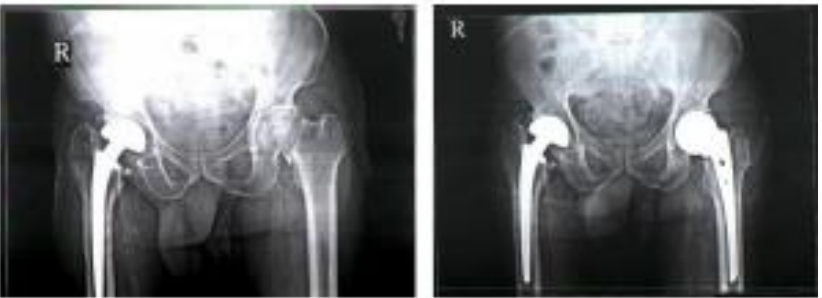

FOLLOW UP
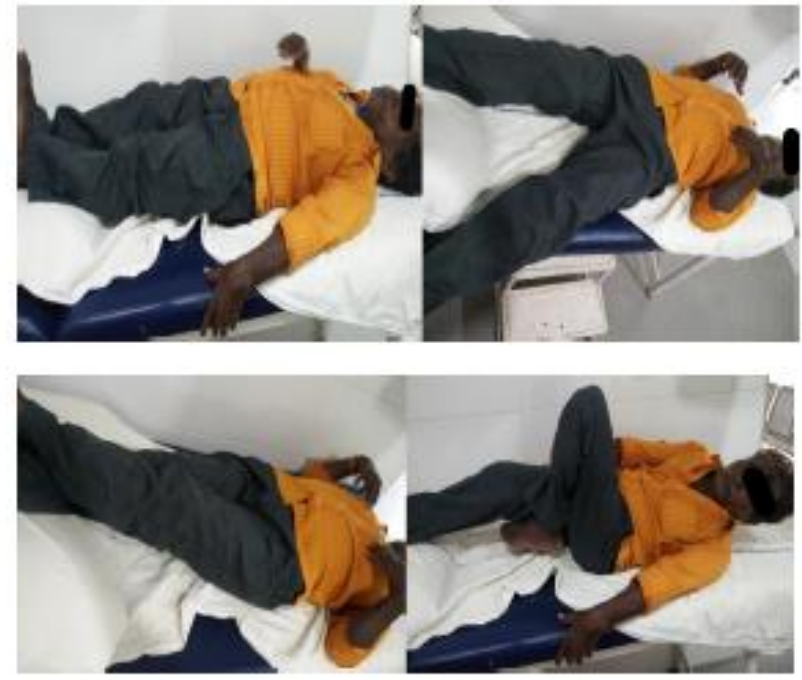

\section{Discussion}

The aim of treatment for intracapsular neck of femur fracture patients is to return to preinjury mobility status as early as possible. Hemiarthoplasty using Austin Moore prosthesis remains a popular choice in elderly.

The mean age of the patients in the present study was 69 years (60-85). This age limit is arbitrary and can be justifiably reduced when the younger patient is in poor health or have low activity level. The average age of patients in our series is similar to other series 67 years (AK Mishra) ${ }^{[8]}, 67$ years (Anil B Dhule) ${ }^{[10]}$ and 69 years (Shan SA) ${ }^{[4]}$.

The present study had a higher number of females similar to other studies done by Essoh J.B (2006) ${ }^{[11]}$ : 83\%, Syed sahid
Noor (2010) ${ }^{[12]}$ : 57\%, Keren Amit (2014) ${ }^{[7]}:$ 74\%. This is due to the lower peak bone mass and postmenopausal bone loss in women. Women have a skeleton that adapts less well to ageing by periosteal apposition.

Left sided hip fractured was noted in $(53 \%)$ of the subjects. This has been a subject of limited studies. Similar finding were noted in by Kisore Roy ${ }^{[6]} 68 \%$. Majority of our study patients $(73.4 \%)$, sustained the injury due to a trivial trauma like tripping or slipping and $(13.3 \%)$ fall from height and (13.3\%) were by road traffic accident. This is in accordance with the series by Evans ${ }^{[13]}$ and Ingalhikar ${ }^{[14]}$. Falls are a common event, particularly among the elderly. Epidemiologic studies have identified a number of risk factors for this like weakness, balance deficit, gait disorder, visual deficit, etc.

Among all study subjects, $50 \%$ of the subjects had at least one or more systemic co-morbidity, the most common being hypertension, seen in $20 \%$ of patients. Whereas other studies reported $83.3 \%, 33 \%$ and $28.6 \%$ patients had hypertension by Noor et al. ${ }^{[12]}$, Karen $\mathrm{Amit}^{7}$ and Mau Daniel ${ }^{[5]}$ respectively. It was observed that the post-operative rehabilitation of patients was significantly affected by the presence of the above co-morbidities. All the subjects were encouraged to ambulate after 3 days of surgery among which $70 \%$ were able to ambulate after 3 days and $30 \%$ took 5 days. The mean average hospital stay was 14 days, similar to study by Mau $\operatorname{Daniel}^{5}$ (2015) with mean duration of 16 days.

Posterior dislocation rate is reported in many series, Salvatti et al. in 1974 believed that excessive post operatively flexion or rotation with hip adduction is the main cause for dislocation of prosthesis and reported $2.8 \%$ posterior hip dislocations. Karen Amit ${ }^{[7]}$ in 2014 reported 1.25\% had dislocation in his studies. None of our study patients had a post-operative dislocation of the prosthesis. This was because meticulous attention was given to insertion of prosthesis in 15-20 degrees anteversion, valgus positioning, suturing the posterior capsule and the short external rotators and keeping the limb in slight abduction post-operatively. Patients were also explained in the immediate post-operative period about the risk of dislocation and were advised not to squat or sit cross leg.

Intra-operative blood loss during the procedure was less than $500 \mathrm{ml}$ in $66.6 \%$, less than $750 \mathrm{ml}$ in $26.7 \%$ and more than $750 \mathrm{ml}$ in $6.7 \%$ which doesn't had any effect on final outcomes. In this study $13 \%$ subjects had complication among which 2 had superficial infections and 2 had bed sore which was treated with regular dressings and antibiotics.

Most commonly used prosthesis size was 47 in this study. Similar findings of 47 sizes were noted in studies done by Mau Daniel ${ }^{[5]}$ (2015).

Garden type III and IV were $40 \%$ and $47 \%$ respectively were found in this study. Saeed Ali Shan ${ }^{[4]}$ (2015) reported type III (65\%) and type IV (35\%). Karen Amit ${ }^{[7]}$ (2014) reported type III $(30 \%)$ and type IV $(62.5 \%)$.

The result at average of 6 months in this study was analyzed by Harris hip score and found to be Excellent $47 \%$, Good $27 \%$, fair $20 \%$ and poor in $6.6 \%$. Laghari et al. ${ }^{[3]}$ (2014) reported Excellent 44\%, Good 27\%, Fair 20\% and Poor in 9\%. Our results seem to suggest that Austin Moore prosthesis gives a better function, safe operation, lesser pain and improved gait function outcome even in elderly with significant medical problems with very low rates of immediate and late complications.

\section{Conclusion}

Hemiarthroplasty for fracture neck of femur is a good option 
in elderly patients. The mortality and morbidity are not high, operative procedure is simple, complications are less disabling. Early functional results are satisfactory. The complications are less disabling, weight bearing is early and early functional results are satisfactory.

Our early and short term results are encouraging and promising, long term results will be studied in future and compared with other long term follow up studies.

\section{References}

1. Merchant RA, Lui KL, Ismail NH, Wong HP, Sitoh Y. The relationship between postoperative complications and outcome after hip fracture surgery. Ann Aced Med Singapore 2005; 34:16-38.

2. Anshu S, Gururaj M, Suresh K. Two years outcome of cemented Austin Moore hemiarthroplasty for fracture neck femur. Journal of Dental and Medical Sciences. 2013; 11(6):10-15.

3. Laghari MA, Pahore MK, Maher IK, Arain MS. Femoral neck fracture; outcome of unipolar hemiarthoplasty in elderly patients. Professional Med J. 2014; 21(5):874878.

4. Shah SA, Memon A, Pirwani M. Outcome of Femural Neck Fracture Treated by Austin - Moor Hemiarthoplasty in Elderly Patients. Med Forum. 2015; 26(1):45-49.

5. Daniel M, Mohammed S, Francis A, William Y, Joseph $\mathrm{K}$, Cornilius E. Early result of hemiarthroplasty in elderly patients with fracture neck of femur. Nigerian Medical Journal: Journal of the Nigeria Medical Association. 2015; 56(1):64-68.

6. Kishore Roy. Management of Intra Capsular Fracture Neck of Femur with Austin Moore's Hemiarthroplasty"A Clinical Study. Indian Journal of Applied Research. 2014; 4(12):371-75.

7. Amit K, Yaron B, Alexander L, Rostislav N, David R. Functional Outcome after Partial Hip Replacement for Femoral Neck Fracture (Subcapital Fracture) with Austin Moore Prosthesis. J Trauma Treat. 2014; 3:188.

8. Mishra AK, Chalise PK, Shah SB, Adhikari V, Singh RP. Comparative study in surgical outcome of intracapsular fracture neck of femur in active elderly patients treated with hemiarthroplasty with Austin Moore's and Bipolar prosthesis. Nepal Med Coll J. 2013; 15(1):81-83.

9. Stavrakis T, Lyras D, Kremmidas N, Hemiarthoplasty C. for fracture of the femur-A comparative study. JBJS, 2008; 59:63-66.

10. Dhule AB, Ansari A, Patil A. Minimal Incision Surgery for Austin Moore Prosthesis in Intracapsular Fracture Neck Femur. Journal of Trauma \& Orthopaedics. 2015; 10(1):18-20.

11. Essoh JB, Sie MD, Aka D et al. Austin Moore Hemiarthoplasty for Displaced Neck fracture in Patients Aged 55 Years and above. An Ivorian Experience. NJOT, 2006; 1:8-13

12. Syed SN, Niaz H, Imran J. Outcome of Austin Moore hemiarthroplasty in Elderly patients with fracture neck of femur. The journal of Pakisthan orthopaedic Association. 2010; 22:14-19.

13. Evans CM. Endoprosthesis as primary treatment of femoral neck fracture. Clin Orthop. 1973; 92:69-76.

14. Ingalhailkar VT, Shekar Kumta. Fracture neck femur anatomical and biomechanical aspects. Clin Orthop. 1987; 98:35-9. 